\title{
Preparation of Chitosan Scaffolds for Tissue Engineering using Freeze drying Technology
}

\author{
Tarun Garg, Arsh Chanana, Ravi Joshi \\ Seth G.L.Bihani S.D.college of technical education, Sri Ganganagar
}

\section{INTRODUCTION}

Chitosan has been processed in several forms to be used in tissue engineering applications, namely, membranes, particles, fibers and 3-D fiber meshes. Chitosan may also be used as a drug delivery carrier, able to carry active agents or biomolecules and growth factors. The preparation of these systems normally envolves freeze drying or lyophilizing a chitosan gel solution [1].

\section{MATERIALS AND METHODS}

\section{FREEZE-DRYING METHOD}

Porous chitosan scaffold formulation was fabricated using freeze- drying method. Briefly chitosan was dissolved in $0.2 \mathrm{M}$ glacial acetic acid and solution was stored for 1 day at room temperature. After 1 day, solution was poured into stainless steel mould and mould was stored in deep freezer at $-70^{\circ} \mathrm{C}$ for 5 days. After 5 days, mould was placed in lyophiliser (Martin Christ alpha 1-2 LD plus, Germany) for 3 days. In the lyophiliser, preparation faced three phases. The first phase was freezing phase - sample was exposed upto $\left(-40^{\circ} \mathrm{C}\right.$, vacuum $\left.6.4 \mathrm{mbar}\right)$ for $10 \mathrm{~min}$. The second phase was warm up vacuum pump phase - sample was exposed upto $\left(-15^{\circ} \mathrm{C}\right.$, vacuum $\left.1.4 \mathrm{mbar}\right)$ for $20 \mathrm{~min}$. The third phase was main drying phase sample was exposed upto $\left(30^{\circ} \mathrm{C}\right.$, vacuum $\left.0.98 \mathrm{mbar}\right)$ for 3 days and after 3 days, blank porous chitosan scaffold was prepared [2].

\section{SCAFFOLD CHARACTERIZATION}

Scanning Electron Microscopy - SEM: The morphology and size of the scaffold formulations were examined using scanning electron microscopy (SEM) (Jeol EVO-50, Japan). SEM figures of these scaffold formulations were taken after gold coating. The sample was placed on the grid and the grid was allowed to dry at ambient temperature and samples were viewed under scanning electron microscope and photographs were taken at suitable magnification [3].

\section{RESULTS AND DISCUSSION}

Chitosan scaffold formulations were white in the dry form, smooth, soft, sponge-like, flexible and strong enough to handle in dry conditions without deformation. The photographs and SEM micrographs of scaffold formulation was shown in Fig. 1. The SEM images show that 3D pore microstructures in all chitosan scaffolds were heterogeneous, with well interconnected pores. The mean diameter of pores on scaffold formulation was found in the range of 10-20 $\mu \mathrm{m}$.
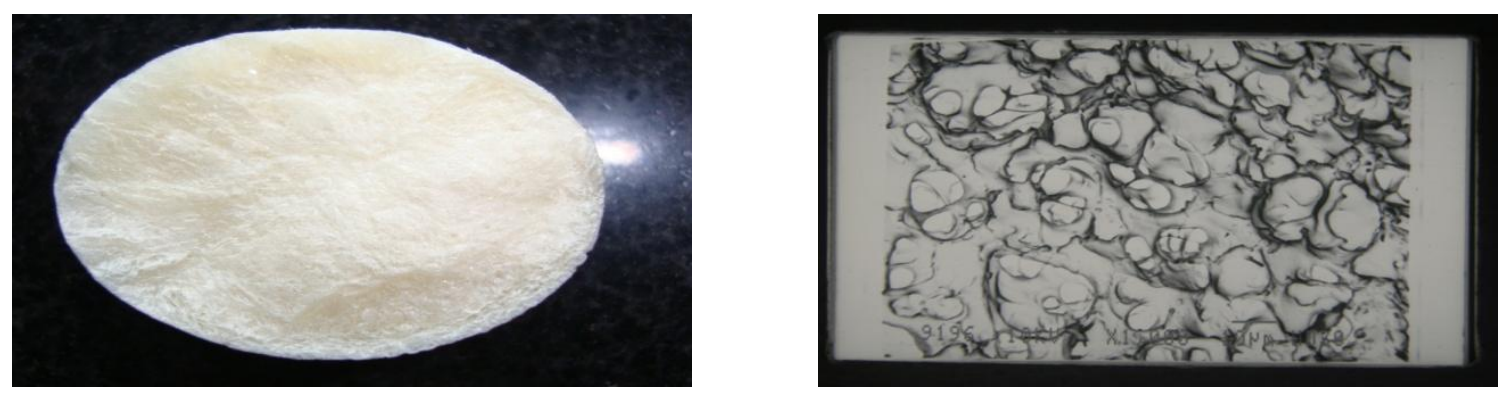

Fig.1. Characterization of chitosan porous matrix scaffold formulation. Photographs of top and SEM views of scaffold formulation respectively.

porous chitosan scaffold formulations were successfully prepared by the freeze-drying method. Freeze-drying method allow a faster preparation, highly porous structure with high pore inter-connectivity. Main advantage of this technique is that, it neither requires high temperature nor separate leaching step. The pore size can be controlled by optimizing the freezing rate and $\mathrm{pH}$; a fast freezing rate produces smaller pores. Freezing temperature, vacuum pressure and time period are very important factors which effect the formation of porous scaffold. 


\section{CONCLUSIONS}

In this work we evaluate the feasibility of processing chitosan 3D scaffolds for tissue engineering applications using freeze drying technology. Freeze drying technology was used to precipitate chitosan from acetic acid solutions and used successfully as a drug delivery carrier, able to carry active agents or biomolecules and growth factors.

\section{REFERENCES}

[1]. T. C. Santos, A. P. Marques, S. S. Silva, J. M. Oliveira, J. F. Mano, A. G. Castro, R. L. Reis, Journal of Biotechnology, 132,2007,218-226.

[2]. S.V. Madihally, H.W.T. Matthew, Porous chitosan scaffolds for tissue engineering, Biomaterials, 20, 1999, 1133-1142.

[3]. H.W. Kim, J.C. Knowles, H. Kim, Hydroxyapatite/poly(e-caprolactone) composite coatings on hydroxyapatite porous bone scaffold for drug delivery, Biomaterials,25, 2004, 1279-1287. 